Research Paper

\title{
Significantly higher pathologic complete response (PCR) after the concurrent use of trastuzumab and anthracycline-based neoadjuvant chemotherapy for HER2-positive breast cancer: Evidence from a meta-analysis of randomized controlled trials
}

\author{
Yu-tuan $\mathrm{Wu}^{1^{*}}$, Zhou $\mathrm{Xu}^{1^{*}}$, Bilal Arshad ${ }^{*}$, Jiu-song $\mathrm{Wu}^{2^{*}}$, Ke Zhang ${ }^{*}$, He Wu ${ }^{1}$, Xin $\mathrm{Li}^{1}$, Hao Li ${ }^{1}$, Ying-cun $\mathrm{Li}^{2}$, \\ Zhong-liang Wang ${ }^{3}$, Kai-nan Wu${ }^{1}$, Ling-quan Kong ${ }^{1 凶}$ \\ 1. Department of Endocrine and Breast Surgery, the First Affiliated Hospital of Chongqing Medical University, Chongqing 400016, China \\ 2. Department of General Surgery, Children's Hospital of Chongqing Medical University, Chongqing 400020, China \\ 3. Department of Orthopedics, Children's Hospital of Chongqing Medical University, Chongqing 400020, China \\ *These authors have contributed equally to this work. \\ $\square$ Corresponding author: Ling-quan Kong, E-mail: huihuikp@163.com \\ (c) Ivyspring International Publisher. This is an open access article distributed under the terms of the Creative Commons Attribution (CC BY-NC) license \\ (https://creativecommons.org/licenses/by-nc/4.0/). See http://ivyspring.com/terms for full terms and conditions.
}

Received: 2018.01.02; Accepted: 2018.03.21; Published: 2018.08.06

\begin{abstract}
Objectives: To investigate the effect of the concurrent use of trastuzumab and anthracycline-based neoadjuvant chemotherapy (NAC) for HER2-positive breast cancer in terms of pCR and cardiotoxicity.

Methods: We systematically searched Pubmed, Embase, Cochrane and SinoMed databases from inception until 1 July 2017 for relevant articles of randomized controlled studies. After identified all relevant studies that reported the concurrent use of trastuzumab and anthracycline-based NAC for HER2-positive locally advanced breast cancer, five eligible randomized studies were extracted relevant data and assessed for design and quality, and the meta-analysis was conducted to evaluate the risk ratio (RR) of $p C R$ and other interesting outcomes, such as left ventricular ejection fraction (LVEF) decrease more than $10 \%$, responses, recurrence free survival (RFS) and overall survival (OS).

Results: A total of five randomized controlled studies were included in the meta-analysis, including 232 HER2-positive locally advanced breast cancer patients received the concurrent use of trastuzumab and anthracycline-based NAC. The results showed that the $P C R$ rate was significantly higher in the group received the concurrent use of trastuzumab and anthracycline-based NAC $(48 \%)$ than that in the non-concurrent use of trastuzumab and anthracycline-based NAC group (26\%) (RR: 1.76, 95\%Cl: 1.37-2.26, $\mathrm{p}<0.0001$ ). Besides, higher rate of RFS (RR: $1.14,95 \% \mathrm{Cl}: 1.03-1.26, p=0.009)$ was observed in the concurrent use of trastuzumab and anthracycline-based NAC group. No significant differences in LVEF decreased more than $10 \%(p=0.50)$ between both groups.

Conclusions: Our meta-analysis of randomized controlled studies showed that PCR rates are significantly higher in the concurrent use of trastuzumab and anthracycline-based NAC compared with the non-concurrent use of trastuzumab and anthracycline-based NAC for certain HER2-positive breast cancer, meanwhile without significant increase of the cardiotoxicity.
\end{abstract}

Key words: Breast cancer; Neoadjuvant chemotherapy; Pathologic complete response (pCR); Human epidermal growth factor receptor 2 (HER2); Meta-analysis

\section{Introduction}

Neoadjuvant chemotherapy (NAC) has become an essential and standard approach for the treatment of locally advanced breast cancer, which would cure distant micro-metastases, downstage tumors, 
improve operability and make breast conservation surgery possible[1,2]. The responses to the NAC in the breast cancer patients would partly predict the prognosis of the patients, so better responses to the NAC are more likely to obtain better outcomes. Meanwhile, different subtypes of breast cancer and different NAC regimens may predict different responses to preoperative chemotherapy [3].

According to the molecular subtyping of breast cancer, which based on the status of hormone receptors and human epidermal growth factor receptor 2 (HER2), 25\%-30\% breast cancer with overexpression or amplification of HER2, which is defined as HER2-positive breast cancer and indicated active proliferation of tumorigenesis [4, 5]. HER2-positive breast cancer was reported to be resistant to certain chemotherapy agents, such as cyclophosphamide, methotrexate and fluorouracil [6]. However, HER2-positive tumors were reported to be high sensitive to anthracyclines- or taxanescontaining chemotherapy [7]. Anthracycline-based regimen is one of the most frequent treatments in NAC of breast cancer, and anthracycline-based regimens are superior to non-anthracycline-based regimens for HER2-positive tumors [7]. Besides, survival benefit of HER2-positive breast cancer patients has dramatically improved since trastuzumab, the HER2-targeted drug, has become available in the treatment of HER2-potitive breast cancer $[8,9]$. In previous randomized studies, NAC of anthracycline-based regimen concurrent with trastuzumab showed a favorable efficacy in local advanced HER2-positive breast cancer, which had not caused significant increase of cardiotoxicity [10-14]. However, in a randomized study, cardiac dysfunction was occurred in $27 \%$ of the HER2-positive metastatic breast cancer patients who received trastuzumab and anthracycline-based combination therapy [5]. Although no significant increase in survival benefit after NAC, several studies have shown that significant improvement of outcomes were obtained when patients achieved pathologic complete response (pCR) [15-17]. It is emphasized that the aim of NAC for locally advanced breast cancer is not only to downstage tumors and improve operability, but also to achieve pCR. Therefore, it is important to optimize the NAC regimen for locally advanced breast cancer. However, the $\mathrm{pCR}$ and cardiotoxicity of the concurrent use of trastuzumab and anthracyclinebased NAC is controversial [18].

Here, we perform a meta-analysis of randomized controlled studies to compare the $\mathrm{pCR}$ rate of concurrent versus non-concurrent use of trastuzumab and anthracycline-based NAC in HER2-positive locally advanced breast cancer.

\section{Materials and Methods}

The systematic review and meta-analysis was conducted in accordance with PRISMA guidelines [19]. This study was conducted in accordance with an established protocol and prospectively registered in PROSPERO (International prospective register of systematic reviews) [20], and the registration information is available on https://www.crd .york.ac.uk/PROSPERO/ (Registration number: CRD42017071432).

\section{Eligibility criteria}

We considered randomized studies that had studied the concurrent use of trastuzumab and anthracycline-based NAC (experiment group) with a control group (Non-concurrent use of trastuzumab and anthracycline-based NAC, such as anthracycline-based NAC alone or trastuzumab plus non-anthracycline-based NAC) for HER2-positive breast cancer. Randomized controlled studies with the concurrent use of trastuzumab and anthracyclinebased NAC were eligible for meta-analysis if they reported the data of pCR. Studies were ineligible: (1) reviews, case reports and non-randomized studies. (2) No experiment or control group or unable to extract relevant data of interesting outcomes. (3) Cases with metastasis or coexist of other malignancies. (4) Cases were not HER2-positive breast cancer patients. HER2-positive breast cancer is defined as HER2 immunohistochemistry score of $3+$ or fluorescence in situ hybridization (FISH) indicates HER2 gene amplification.

\section{Search strategy}

We searched Pubmed, Embase, Cochrane and SinoMed (Chinese Biomedical Database) databases from inception until 1 July 2017 for relevant articles in any language. The references were searched by a combination of medical subject heading terms and/or free text words, such as "breast neoplasm", "breast cancer", "breast carcinoma", "neoadjuvant", "preoperative", "anthracycline", "doxorubicin", "epirubicin", "herceptin" and "trastuzumab" (S1 Appendix Data). Two investigators (JSW and KZ) independently performed the references search, a third investigator (YTW) was consulted when disagreement arose.

\section{Outcome measures}

The primary outcomes were the rates and the risk ratio (RR) of pCR compared the concurrent with non-concurrent use of trastuzumab and anthracycline-based NAC for HER2-positive breast cancer, and the secondary outcomes was the RR of left ventricular ejection fraction (LVEF) decrease more 


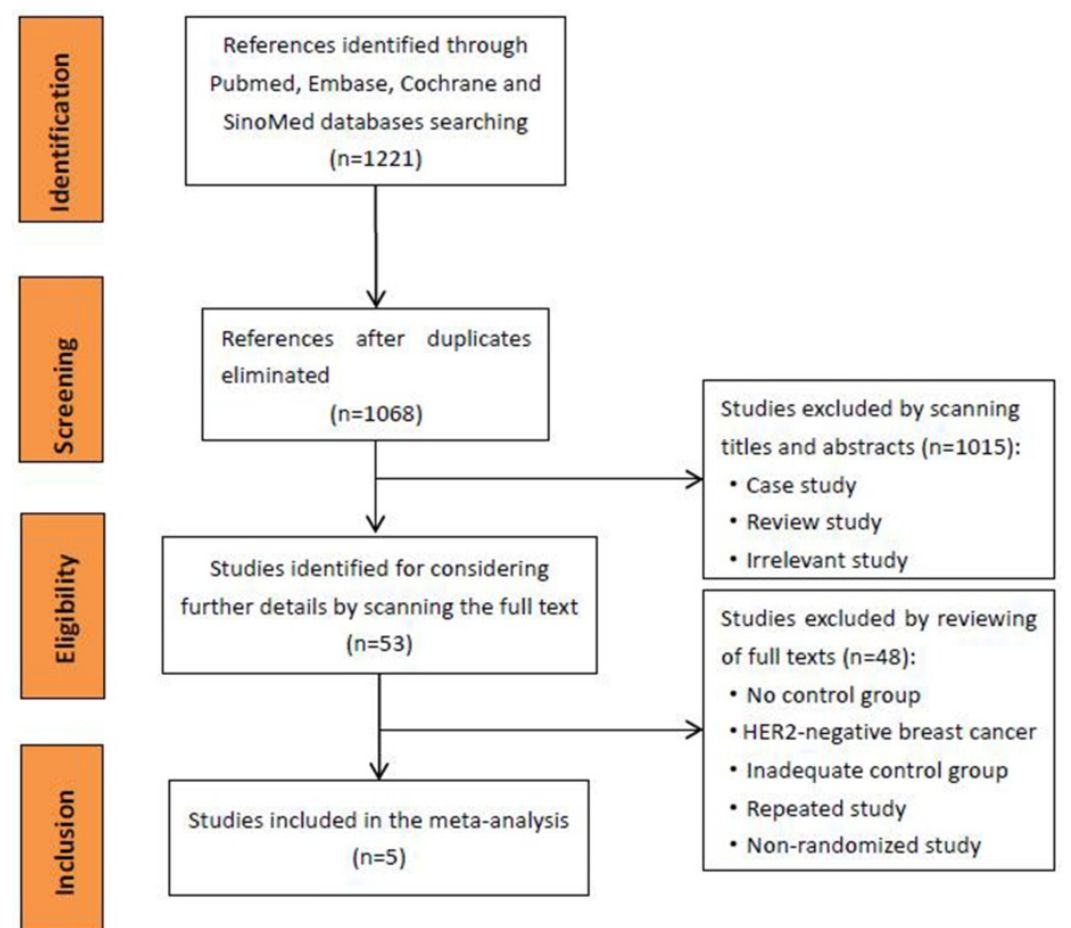

Figure 1. Preferences selection flow diagram

than $10 \%$, cardiac failure $(\mathrm{CF})$, responses (complete response and partial response), breast conversion surgery (BCS), recurrence free survival (RFS) and overall survival (OS).

\section{Study selection}

All 1221 references were identified after databases searched. After duplicates removed, two researchers independently assessed the eligible studies, titles and abstracts of articles were scanned. After that, we reviewed the full text of possible articles according to the inclusion/exclusion criteria. Finally, total 5 studies [10-14] were included in the meta-analysis (Fig 1).

\section{Data extraction and quality assessment}

Two researchers (ZX and BA) independently extracted information of the eligible studies using electronic tables. The following items were extracted from eligible articles: Basic information, including the year of study publication, country, study design, sample size, age, chemotherapy regimen, type of cancer, time of follow-up. Besides, data of outcomes information was collected.

The bias risk assessment was conducted according to the Cochrane Collaboration Risk of Bias Assessment Tool (http://www.cochrane.org). Two reviewers (JSW and KZ) independently evaluated the methodological quality, a third investigator (YTW) was consulted when disagreement arose between the prior reviewers. The assessment has seven parameters of quality assessment for randomized controlled studies, including random sequence generation, allocation concealment, blinding of participants and personnel, blinding of outcome assessment, incomplete outcome data, selective bias and other biases. Each parameter has three categories of biases: low risk of bias, unclear risk of bias and high risk of bias. All studies were deemed to have a high risk of blinding of participants and personnel because it was difficult to make patients blinding in relevant trials. After evaluation, all studies were assessed to have appropriate quality of methodology.

\section{Statistical analysis}

We pooled the absolute rate of $\mathrm{pCR}$ in the experiment group and control group, and risk ratio (RR) with 95\% confidence intervals (CI) of pCR compared the concurrent with non-concurrent use of trastuzumab and anthracycline-based NAC for HER2-positive breast cancer. The secondary outcomes were also pooled. The meta-analysis statistics was carried out using the Cochrane Collaboration's Review Manager Software (RevMan, version 5.3; Oxford, United Kingdom) and R software (version 3.3.2, R Foundation for Statistical Computing). Probability values were two-sided, and $\mathrm{P}<0.05$ was considered of statistical significance. Statistical heterogeneity was evaluated using the I-squared $\left(\mathrm{I}^{2}\right)$ and chi-squared $\left(\chi^{2}\right)$ tests. $\mathrm{I}^{2}$ values of $25 \%, 50 \%, 75 \%$ indicated low, moderate and high level of heterogeneity, respectively. Data was not pooled if the $\mathrm{I}^{2}$ was greater than $40 \%$. A p value of $<0.1$ for $\chi^{2}$ was defined to indicate the presence of heterogeneity. Results were pooled using the maximum likelihood estimation, a random effect model was used for analysis if heterogeneity existed, and otherwise a fixed effect model was used. Besides, sensitivity analysis was performed by excluding the heterogeneity study or the study of the least sample size depending on the presence or absence of significant heterogeneity. Funnel plots and the Egger's test of funnel plot asymmetry were used to evaluate publication bias.

\section{Results}

\section{Description of included studies}

In total, we included 5 randomized controlled studies [10-14] in concordance with eligibility criteria 
after ineligible studies were excluded from all the identified references (Fig 1), which including 232 [Median age: 48.5 (range: $21-71$ )] and 212 [Median age: 46.8 (range: 25-75)] HER2-positive breast cancer patients concurrent and non-concurrent use of trastuzumab and anthracycline-based NAC, respectively. We summarized the baseline study characteristics in Table 1 and extracted data in S1 table. The 5 studies included two from America, two from China and one study was international multicenter study (six countries and 27 centers).

Table 1. Characteristics of studies included in the meta-analysis

\begin{tabular}{|c|c|c|c|c|c|c|c|c|c|c|}
\hline $\begin{array}{l}\text { Study, } \\
\text { Year }\end{array}$ & Country & $\begin{array}{l}\text { Type of } \\
\text { study }\end{array}$ & $\begin{array}{l}\text { Total } \\
\text { participants } \\
\text { (EH/No } \\
\text { EH)* }\end{array}$ & $\begin{array}{l}\text { Median age } \\
\text { (range)(years) }\end{array}$ & Chemotherapy regimen & $\begin{array}{l}\text { Baseline left } \\
\text { ventricular } \\
\text { ejection } \\
\text { fraction (LVEF) }\end{array}$ & Anthracycline & $\begin{array}{l}\text { Type of } \\
\text { cancer }\end{array}$ & $\begin{array}{l}\text { Outcome } \\
\text { measures }\end{array}$ & $\begin{array}{l}\text { Median } \\
\text { of } \\
\text { follow-up } \\
\text { (months) }\end{array}$ \\
\hline $\begin{array}{l}\text { Buzdar et } \\
\text { al, } 2005\end{array}$ & USA & $\begin{array}{l}\text { Prospective } \\
\text { randomized } \\
\text { trial }\end{array}$ & $42(23 / 19)$ & $\begin{array}{l}\text { EH:52(29-71) } \\
\text { No } \\
\text { EH:48(25-75) }\end{array}$ & $\begin{array}{l}\text { Paclitaxel }\left(225 \mathrm{mg} / \mathrm{m}^{2}\right) \text {, } \\
\text { FEC }(\text { fluorouracil } \\
500 \mathrm{mg} / \mathrm{m}^{2} \text {, day } 1,4 ; \\
\text { cyclophosphamide } \\
500 \mathrm{mg} / \mathrm{m}^{2} \text {, day } 1 ; \\
\text { epirubicin } 75 \mathrm{mg} / \mathrm{m}^{2} \text {, day } \\
1) \text {, trastuzumab }(4 \mathrm{mg} / \mathrm{kg} \text {, } \\
\text { day } 1 \text { of the first cycle, } \\
\text { followed by } 2 \mathrm{mg} / \mathrm{kg} \text {, } \\
\text { weekly). Four cycles of } \\
\text { paclitaxel followed by four } \\
\text { cycles of FEC,cycles } \\
\text { repeated every } 3 \text { weeks, } \\
\text { with or without } \\
\text { simultaneous } \\
\text { trastuzumab. }\end{array}$ & $\begin{array}{l}\text { Patients with a } \\
\text { history of } \\
\text { uncompensated } \\
\text { congestive heart } \\
\text { failure or a } \\
\text { cardiac ejection } \\
\text { fraction less } \\
\text { than } 45 \% \text { were } \\
\text { excluded. }\end{array}$ & Epirubicin & $\begin{array}{l}\text { HER-2 } \\
\text { positive and } \\
\text { clinical stage } \\
\text { II to IIIa. }\end{array}$ & $\begin{array}{l}\text { pCR; CR; PR; } \\
\text { RFS; Rate of } \\
\text { breast } \\
\text { conservation; } \\
\text {;Cardiac } \\
\text { ejection } \\
\text { fraction; } \\
\text { Cardiac } \\
\text { failure. }\end{array}$ & 20 \\
\hline $\begin{array}{l}\text { Buzdar et } \\
\text { al, } 2007\end{array}$ & USA & $\begin{array}{l}\text { Prospective } \\
\text { randomized } \\
\text { trial }\end{array}$ & $41(22 / 19)$ & $\begin{array}{l}\text { EH:51(21-70) } \\
\text { No } \\
\text { EH:48(25-75) }\end{array}$ & $\begin{array}{l}\text { Four cycles of paclitaxel } \\
\text { ( } 225 \mathrm{mg} / \mathrm{m}^{2} \text {, every } 3 \\
\text { weeks), followed by four } \\
\text { cycles of FEC (fluorouracil } \\
500 \mathrm{mg} / \mathrm{m}^{2} \text {, day } 1,4 ; \\
\text { cyclophosphamide } \\
500 \mathrm{mg} / \mathrm{m}^{2} \text {, day } 1 ; \\
\text { epirubicin } 75 \mathrm{mg} / \mathrm{m}^{2}, \text { day } \\
\text { 1), trastuzumab }(4 \mathrm{mg} / \mathrm{kg} \text {, } \\
\text { day } 1 \text { of the first cycle, } \\
\text { followed by } 2 \mathrm{mg} / \mathrm{kg} \\
\text { weekly). } \\
\text { P-FEC/PH-FECH. }\end{array}$ & $\begin{array}{l}\text { Patients with a } \\
\text { history of } \\
\text { uncompensated } \\
\text { congestive heart } \\
\text { failure or a } \\
\text { cardiac ejection } \\
\text { fraction less } \\
\text { than } 45 \% \text { were } \\
\text { excluded. }\end{array}$ & Epirubicin & $\begin{array}{l}\text { HER-2 } \\
\text { positive and } \\
\text { clinical stage } \\
\text { II to IIIa. }\end{array}$ & $\begin{array}{l}\text { pCR; RFS; } \\
\text { Cardiac } \\
\text { ejection } \\
\text { fraction; } \\
\text { Cardiac } \\
\text { failure. }\end{array}$ & 36.1 \\
\hline $\begin{array}{l}\text { Gianni et } \\
\text { al, } 2010\end{array}$ & $\begin{array}{l}\text { International } \\
\text { multicenter } \\
\text { study (six } \\
\text { countries } \\
\text { and } 27 \\
\text { centers) }\end{array}$ & $\begin{array}{l}\text { Prospective } \\
\text { phase III } \\
\text { randomized } \\
\text { trial }\end{array}$ & $235(117 / 118)$ & $\begin{array}{l}<50 \text { years } \\
\text { EH:50p No } \\
\text { EH:50p } \\
>50 \text { years } \\
\text { EH:67p No } \\
\text { EH:68p }\end{array}$ & $\begin{array}{l}\text { Doxorubicin } 60 \mathrm{mg} / \mathrm{m}^{2} \\
\text { plus paclitaxel } 150 \mathrm{mg} / \mathrm{m}^{2} \text {, } \\
\text { every } 3 \text { weeks for three } \\
\text { cycles, followed by } \\
\text { paclitaxel } 175 \mathrm{mg} / \mathrm{m}^{2} \\
\text { administered every } 3 \\
\text { weeks for four cycles. } \\
\text { Cyclophosphamide } \\
600 \mathrm{mg} / \mathrm{m}^{2} \text { and } \\
\text { fluorouracil } 600 \mathrm{mg} / \mathrm{m}^{2} \\
\text { were then given on days } 1 \\
\text { and } 8 \text { every } 4 \text { weeks for } \\
\text { three cycles. Trastuzumab } \\
8 \mathrm{mg} / \mathrm{kg} \text { loading dose, } \\
\text { followed by } 6 \mathrm{mg} / \mathrm{kg}, \\
\text { every } 3 \text { or } 4 \text { weeks. } \\
\text { TEH-FCH/TE-FC. }\end{array}$ & $\begin{array}{l}\text { EH:63\%(55-82) } \\
\text { No } \\
\text { EH:63\%(55-89) }\end{array}$ & Doxorubicin & $\begin{array}{l}\text { HER-2 } \\
\text { positive } \\
\text { locally } \\
\text { advanced or } \\
\text { inflammatory } \\
\text { breast cancer. }\end{array}$ & $\begin{array}{l}\text { pCR; RFS; } \\
\text { OS; Cardiac } \\
\text { ejection } \\
\text { fraction. }\end{array}$ & 38.4 \\
\hline $\begin{array}{l}\text { Huang et } \\
\text { al, } 2015\end{array}$ & China & $\begin{array}{l}\text { Phase II } \\
\text { randomized } \\
\text { trial }\end{array}$ & $87(41 / 46)$ & $\begin{array}{l}\text { EH:47.5(30-63) } \\
\text { No } \\
\text { EH:48(29-65) }\end{array}$ & $\begin{array}{l}\text { Paclitaxel }\left(75 \mathrm{mg} / \mathrm{m}^{2} \text {, }\right. \\
\text { weekly), trastuzumab } \\
\text { ( } 4 \mathrm{mg} / \mathrm{kg} \text { loading dose } \\
\text { followed by } 2 \mathrm{mg} / \mathrm{kg}) \text {, } \\
\text { carboplatin (AUC=2, } \\
\text { weekly), epirubicin } \\
\text { ( } 75 \mathrm{mg} / \mathrm{m}^{2} \text {, every } 3 \text { weeks). } \\
\text { At least } 4 \text { cycles but no } \\
\text { more than } 6 \text { cycles. } \\
\text { PEH/PCH. }\end{array}$ & $\begin{array}{l}\text { EH:67\%(58-79) } \\
\text { No } \\
\text { EH:65\%(56.5-83) }\end{array}$ & Epirubicin & $\begin{array}{l}\text { HER-2 } \\
\text { positive and } \\
\text { clinical stage } \\
\text { II to III. }\end{array}$ & $\begin{array}{l}\text { pCR; CR; PR; } \\
\text { Cardiac } \\
\text { ejection } \\
\text { fraction; } \\
\text { Cardiac } \\
\text { failure. }\end{array}$ & NR \\
\hline $\begin{array}{l}\text { Yu et al, } \\
2016\end{array}$ & China & $\begin{array}{l}\text { Randomized } \\
\text { controlled } \\
\text { trial }\end{array}$ & $58(29 / 29)$ & $\begin{array}{l}\text { EH:45.2(35-62) } \\
\text { No } \\
\text { EH:44.1(33-59) }\end{array}$ & $\begin{array}{l}\text { Epirubicin } 40 \mathrm{mg} / \mathrm{m}^{2} \text {, } \\
\text { docetaxel } 60 \mathrm{mg} / \mathrm{m}^{2}, \\
\text { trastuzumab } 4 \mathrm{mg} / \mathrm{kg} \text {, } \\
\text { every } 3 \text { weeks, } 4 \text { cycles. } \\
\text { TEH/TE. }\end{array}$ & NR & Epirubicin & $\begin{array}{l}\text { HER-2 } \\
\text { positive and } \\
\text { clinical stage } \\
\text { II to III. }\end{array}$ & $\begin{array}{l}\text { pCR; CR; PR; } \\
\text { OS; RFS. }\end{array}$ & 60 \\
\hline
\end{tabular}


We evaluated the quality of the included studies using Cochrane Collaboration Risk of Bias Assessment Tool in S2 table. As a result, all of the included studies were of eligible quality, which indicated that all the included studies were reliable. Besides, we assessed the publication bias of the included studies using symmetrical funnel plot analysis and Egger's tests, and the result showed no significant publication bias was found. Meanwhile, we found no significant between-study heterogeneity $\left(\mathrm{I}^{2}=0 \%\right)$, thus the fixed-effect model was used.

\section{Pathologic complete response}

Total five randomized studies, including 443 patients (232 in the experiment group and 212 in the control group), were analyzed for the pCR rate of HER2-positive breast cancer patients concurrent and non-concurrent use of trastuzumab and anthracycline-based NAC. The absolute pCR rate was pooled to be $48 \%$ (95\% CI: $0.42-0.54$ ) in the concurrent use of trastuzumab and anthracycline-based NAC group and $26 \% \quad(95 \% \mathrm{CI}: 0.21-0.32)$ in the non-concurrent use of trastuzumab and anthracycline-based NAC group (Fig 2).

The $\mathrm{pCR}$ rate was significantly higher in the concurrent use of trastuzumab and anthracyclinebased NAC compared to the group with non-concurrent use of trastuzumab and anthracycline-based NAC, corresponding RR was 1.76 (95\%CI: 1.37-2.26, p<0.0001) (Fig 3). The pCR rate increased from $26 \%$ to $48 \%$, absolute increase of $22 \%$. $\mathrm{I}^{2}<25 \%, \mathrm{p}$ for heterogeneity was $<0.05$, thus a fixed-effect model was used.

A

Study

Buzdar et al, 2005

Buzdar et al, 2007

Gianni et al, 2010

Huang et al, 2015

Yu et al, 2016

Fixed effect model

Random effects model

Heterogeneity: $\mid-$ squared $=15.3 \%$, tau-squared $=0.0011, p=0.3170, \mid$

$\begin{array}{llllll}0.3 & 0.4 & 0.5 & 0.6 & 0.7 & 0.8\end{array}$

B

\section{Study}

Buzdar et al, 2005

Gianni et al, 2010

Huang et al, 2015

Yu et al, 2016

Fixed effect mode

Random effects model

Heterogeneity: $l$-squared $=36.6 \%$, tau-squared $=0.0027, p_{1}=0.192$ ?

$$
\begin{array}{lllll}
0.1 & 0.2 & 0.3 & 0.4 & 0.5
\end{array}
$$

Proportion $\quad 95 \%-\mathrm{Cl}$ W(fixed) W(random)

$\begin{array}{rrr}0.65[0.43 ; 0.84] & 10.7 \% & 12.6 \% \\ 0.55[0.32 ; 0.76] & 9.4 \% & 11.1 \% \\ 0.43[0.34 ; 0.52] & 50.4 \% & 43.0 \% \\ 0.49[0.33 ; 0.65] & 17.3 \% & 19.1 \% \\ 0.48[0.29 ; 0.67] & 12.2 \% & 14.2 \% \\ & & \\ 0.48[0.42 ; 0.54] & 100 \% & -- \\ \mathbf{0 . 4 9}[0.42 ; 0.56] & -- & 100 \%\end{array}$

\section{Proportion $\quad 95 \%-\mathrm{Cl}$ W(fixed) $\mathrm{W}$ (random)}

$\begin{array}{rrrr}0.26[0.09 ; 0.51] & 8.8 \% & 14.3 \% \\ 0.22[0.15 ; 0.31] & 61.7 \% & 44.1 \% \\ 0.39[0.25 ; 0.55] & 17.3 \% & 23.4 \% \\ 0.31[0.15 ; 0.51] & 12.2 \% & 18.3 \% \\ & & \\ 0.26[0.21 ; 0.32] & \mathbf{1 0 0 \%} & - \\ \mathbf{0 . 2 8}[\mathbf{0 . 2 0} ; 0.37] & -- & \mathbf{1 0 0 \%}\end{array}$

Figure 2. The pooled absolute rate of $\mathrm{PCR}$ for the concurrent $(\mathrm{A})$ and non-concurrent $(\mathrm{B})$ use of trastuzumab and anthracycline-based NAC for HER2-positive breast cancer

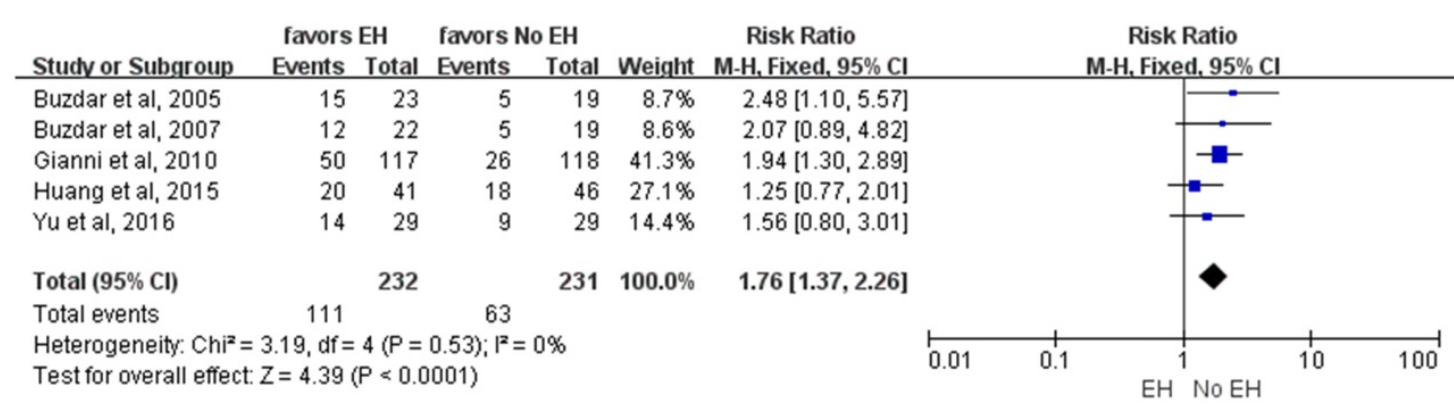

Figure 3. The RR of $p C R$ for the comparison of the concurrent versus non-concurrent use of trastuzumab and anthracycline-based NAC for HER2-positive breast cancer. EH: the group of concurrent use of trastuzumab $(\mathrm{H})$ and anthracycline(E)-based NAC for HER2-positive breast cancer. No EH: the group of non-concurrent use of trastuzumab $(\mathrm{H})$ and anthracycline(E)-based NAC for HER2-positive breast cancer. 


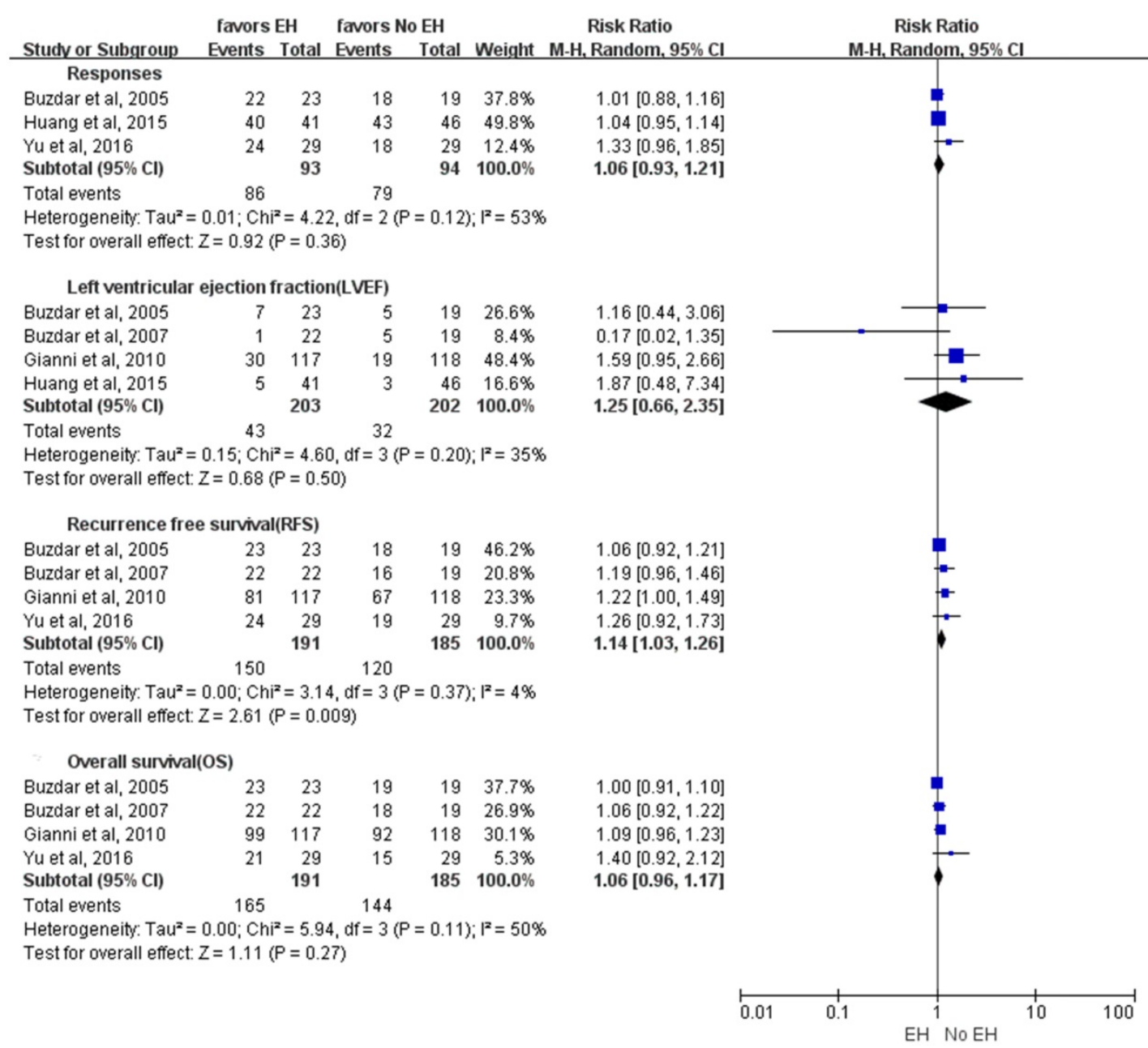

Figure 4. The RR of secondary outcomes for the comparison of the concurrent versus non-concurrent use of trastuzumab and anthracycline-based NAC for HER2-positive breast cancer. EH: the group of concurrent use of trastuzumab(H) and anthracycline(E)-based NAC for HER2-positive breast cancer. No EH: the group of non-concurrent use of trastuzumab $(\mathrm{H})$ and anthracycline $(\mathrm{E})$-based NAC for HER2-positive breast cancer.

\section{Secondary outcomes}

Some secondary outcomes reported in the included studies were pooled. For the rate of responses, no significantly higher responses rate was observed in the concurrent use of trastuzumab and anthracycline-based NAC group (RR: 1.06, 95\%CI: 0.93-1.21, $p=0.36$ ) (Fig 4). During the period of follow-up, the RFS and OS were reported in four studies. Compared with the non-concurrent use of trastuzumab and anthracycline-based NAC group, the concurrent used of trastuzumab and anthracycline-based NAC group had a better RFS (RR: 1.14, 95\% CI: 1.03-1.26, p=0.009) (Fig 4), but the OS had no significant difference (RR: 1.06, 95\%CI: 0.96-1.17, $\mathrm{p}=0.27$ ) (Fig 4). Heterogeneity was observed, a random-effect model was used.

For the cardiotoxicity, four studies had reported the LVEF decrease more than $10 \%$ events. According to our pooled analysis, the LVEF decrease more than $10 \%$ events were not significant different in both groups (RR: 1.25, 95\%CI: 0.66-2.35, p=0.50) (Fig 4).
Besides, only one study reported that two patients developed a reversible symptomatic cardiac failure in the concurrent use of trastuzumab and anthracycline-based NAC group [12]. For the BCS, as reported by Buzdar et al [10], BCS was performed in $10(52.6 \%)$ and $13(56.5 \%)$ patients in the concurrent and non-concurrent use of trastuzumab and anthracycline-based NAC groups, respectively.

\section{Discussion}

This meta-analysis of randomized controlled studies provides a comparison of the $\mathrm{pCR}$ and cardiotoxicity between the concurrent and non-concurrent use of trastuzumab and anthracycline-based NAC for HER2-positive breast cancer. Two previous meta-analysises had suggested that the concurrent use of trastuzumab and NAC for HER2-positive breast cancer would improve the $\mathrm{pCR}$ rate $[21,22]$. However, previous studies did not conducted subgroup analysis for efficacy of the concurrent use of trastuzumab and anthracyclines, corresponding $\mathrm{pCR}$ rates and toxic effects were not 
reported. Considering the cardiotoxicity of both trastuzumab and anthracyclines, the concurrent use of trastuzumab and anthracycline-based NAC for HER2-positive breast cancer patients should be more careful [23-25]. Several randomized studies [10-14] had evaluated the efficacy and toxic effects of the concurrent use of trastuzumab and anthracyclinebased NAC for HER2-positive breast cancer, thus we performed this meta-analysis to make a further study.

Our study suggests that a higher rate of $\mathrm{pCR}$ were acquired in the concurrent use of trastuzumab and anthracycline-based NAC (48\%) compared to the non-concurrent use of trastuzumab and anthracycline-based NAC (26\%) for HER2-positive breast cancer. Besides, during the period of follow-up, the concurrent use of trastuzumab and anthracycline-based NAC had led to a better RFS rate, but the OS was not significantly different. Similar results have been seen in previous studies, the concurrent use of trastuzumab and anthracyclinebased NAC is superior to the non-concurrent use of trastuzumab and anthracycline-based NAC for HER2-positive breast cancer in terms of pCR. NAC for breast cancer patients is focus on reducing the size of the tumor and improving operability, however, $\mathrm{pCR}$ is the most favorable effect in the short period [26-28]. Although the OS is not assured during the short period of follow-up, the pCR is reported to be a valuable subrogate measure for an improved long-term outcome, meanwhile patients without $\mathrm{pCR}$ indicates an increased risk of relapse and death [29-31].

It is known that trastuzumab and anthracyclines are both cardiotoxic drugs, thus the cardiotoxicity may be more severe when they are concurrently used [32-34]. According to this meta-analysis, the number of patients presented an asymptomatic absolute reduction in the LVEF of $10 \%$ had no significant difference in two groups. It is noted that almost all patients were stage II to III HER2-positive breast cancer, and the patients' median age were 48.5 (range: 21-71) and 46.8 (range: 25-75) in the concurrent and the non-concurrent use of trastuzumab and anthracycline-based NAC groups, respectively. The baseline LVEF of all patients were measured by multiple gated acquisition scan or echocardiography before NAC, and the baseline LVEF were favorable and similar in two groups. Based on the certain age and similar baseline LVEF, patients with the concurrent use of trastuzumab and anthracyclinebased NAC didn't show more cardiotoxicity events compared to those with non-concurrent use of trastuzumab and anthracycline-based NAC.

Trastuzumab, a humanized monoclonal antibody, binds to the extracellular juxtamembrane domain of HER2 and inhibits the proliferation and survival of HER2-dependent tumors [9]. The following mechanisms were considered to be action of anthracyclines in cancer cells. First, intercalate into DNA and lead to inhibit synthesis of macromolecules. Second, generate of free radicals and lead to DNA damage or lipid peroxidation. Third, initiate of DNA damage and apoptosis via inhibition of topoisomerase II [35]. Due to the different mechanisms of trastuzumab and anthracyclines, the concurrent use of them indicated an improved $\mathrm{pCR}$ rate in HER2-positive breast cancer. Although trastuzumab and anthracyclines were reported to be associated with an increased risk of cardiotoxicity, especially when concurrent use of them, previous studies[10-14] and this meta-analysis demonstrated that the concurrent use of trastuzumab and anthracyclinebased NAC for certain HER2-positive breast cancer patients was both effective and well tolerated. The $\mathrm{NOAH}$ trial [12] compared the efficacy of the concurrent use of trastuzumab and anthracyclinebased NAC, they reported pCR rate of $38 \%$ and $19 \%$ in the concurrent and non-concurrent use of trastuzumab and anthracycline-based NAC, respectively. Besides, trastuzumab was well tolerated despite concurrent use with anthracyclines [12], and trastuzumab was also cardiac safe during long-term assessment [36]. Therefore, the concurrent use of trastuzumab and anthracycline-based NAC should be considered for locally advanced HER2-positive breast cancer with closely monitoring the cardiac function.

Our meta-analysis of randomized controlled studies has demonstrated the $\mathrm{pCR}$ rate and cardiotoxicity of the concurrent use of trastuzumab and anthracycline-based NAC for HER2-positive breast cancer. To our knowledge, this study is the first meta-analysis of randomized controlled studies making a systematic evaluation about this controversial scientific topic. Meanwhile, this metaanalysis of randomized controlled studies has some limitations. Firstly, we searched several databases for eligible studies, but only five randomized controlled studies, including 443 HER2-positive breast cancer patients, were included. Besides, one study [12] had mixed patients of locally advanced and inflammatory breast cancer. Furthermore, although the NAC were all conducted with anthracycline-based regimens, the NAC regimens were not strictly the same in each included studies, and the durations of NAC were slightly different. Finally, the prognosis of long time survival was not analyzed in detail due to the short and different duration of follow-up in each study. We suggest that further research should be designed to make more understanding about these aspects. 


\section{Conclusions}

Our meta-analysis of randomized controlled studies show that $\mathrm{pCR}$ rates are significantly higher in the concurrent use of trastuzumab and anthracyclinebased NAC compared with the non-concurrent use of trastuzumab and anthracycline-based NAC for certain HER2-positive breast cancer patients, meanwhile without significantly increase of the cardiotoxicity. The available evidences support the concurrent use of trastuzumab and anthracyclinebased NAC for certain HER2-positive breast cancer patients, meanwhile the cardiac function should be monitored closely.

\section{Supplementary Material}

Supplementary tables and appendix.

http://www.jcancer.org/v09p3168s1.pdf

\section{Acknowledgements}

\section{Author Contributions}

YTW, ZX, BA, JSW and KZ conceived and designed the study, conducted the study, provided methodological support, conducted the analyses, interpreted the results and wrote, read and edited the manuscript. YTW, LQK interpreted the results, read and edited the manuscript. HW, XL, HL, YCL, ZLW and KNW conducted the study and read and edited the manuscript. LQK conceived and designed the study, provided methodological support, interpreted the results, guided the analysis and read and edited the manuscript.

\section{Funding}

This study was funded by Graduate Student's Science Innovation Project of Chongqing (CYS16124) and National Natural Science Foundation of China (NSFC) (81372851).

\section{Data sharing statement}

All data are freely available online.

\section{Trial registration number}

PROSPERO (International prospective register of systematic reviews: https://www.crd.york.ac.uk/ PROSPERO/), number: CRD42017071432.

\section{Competing Interests}

The authors have declared that no competing interest exists.

\section{References}

1. Graham PJ, Brar MS, Foster T, et al. Neoadjuvant Chemotherapy for Breast Cancer, Is Practice Changing? A Population-Based Review of Current Surgical Trends. Ann Surg Oncol 2015, 22(10):3376-3382.

2. Untch M, Konecny GE, Paepke S, et al. Current and future role of neoadjuvant therapy for breast cancer. Breast 2014, 23(5):526-537.
3. Colleoni M, Viale G, Zahrieh D, et al. Expression of ER, PgR, HER1, HER2, and response: a study of preoperative chemotherapy. Ann Oncol 2008, 19(3):465-472.

4. Uriarte-Pinto M, Escolano-Pueyo A, Gimeno-Ballester V, et al. Trastuzumab, non-pegylated liposomal-encapsulated doxorubicin and paclitaxel in the neoadjuvant setting of HER-2 positive breast cancer. International journal of clinical pharmacy 2016, 38(2):446-453.

5. Slamon DJ, Leyland-Jones B, Shak S, et al. Use of chemotherapy plus a monoclonal antibody against HER2 for metastatic breast cancer that overexpresses HER2. N Engl J Med 2001, 344(11):783-792.

6. Gusterson BA, Gelber RD, Goldhirsch A, et al. Prognostic importance of c-erbB-2 expression in breast cancer. International (Ludwig) Breast Cancer Study Group. Journal of clinical oncology: official journal of the American Society of Clinical Oncology 1992, 10(7):1049-1056.

7. Pritchard KI, Messersmith H, Elavathil L, et al. HER-2 and topoisomerase II as predictors of response to chemotherapy. Journal of clinical oncology: official journal of the American Society of Clinical Oncology 2008, 26(5):736-744.

8. Cameron D, Piccart-Gebhart MJ, Gelber RD, et al. 11 years' follow-up of trastuzumab after adjuvant chemotherapy in HER2-positive early breast cancer: final analysis of the HERceptin Adjuvant (HERA) trial. The Lancet 2017, 389(10075):1195-1205.

9. Hudis CA. Trastuzumab - Mechanism of Action and Use in Clinical Practice. N Engl J Med 2007, 357(1):39-51.

10. Buzdar AU, Ibrahim NK, Francis D, et al. Significantly higher pathologic complete remission rate after neoadjuvant therapy with trastuzumab, paclitaxel, and epirubicin chemotherapy: Results of a randomized trial in human epidermal growth factor receptor 2-positive operable breast cancer. Journal of Clinical Oncology 2005, 23(16):3676-3685.

11. Buzdar AU, Valero V, Ibrahim NK, et al. Neoadjuvant therapy with paclitaxel followed by 5 -fluorouracil, epirubicin, and cyclophosphamide chemotherapy and concurrent trastuzumab in human epidermal growth factor receptor 2-positive operable breast cancer: an update of the initial randomized study population and data of additional patients treated with the same regimen. Clin Cancer Res 2007, 13(1):228-233.

12. Gianni L, Eiermann W, Semiglazov V, et al. Neoadjuvant chemotherapy with trastuzumab followed by adjuvant trastuzumab versus neoadjuvant chemotherapy alone, in patients with HER2-positive locally advanced breast cancer (the NOAH trial): a randomised controlled superiority trial with a parallel HER2-negative cohort. Lancet (London, England) 2010, 375(9712): 377-384.

13. Huang L, Chen S, Yang W, et al. Efficacy and safety analysis of trastuzumab and paclitaxel based regimen plus carboplatin or epirubicin as neoadjuvant therapy for clinical stage II-III, HER2-positive breast cancer patients: a phase 2, open-label, multicenter, randomized trial. In: Oncotarget. vol. 6; 2015: 18683-18692.

14. Yu S, Shuai L, Ting L, et al. Efficacy of trastuzumab joint neoadjuvant chemotherapy for HER-2 positive breast cancer. The Practical Journal of Cancer 2016, 31(8):1355-1356.

15. Guarneri V, Broglio K, Kau SW, et al. Prognostic value of pathologic complete response after primary chemotherapy in relation to hormone receptor status and other factors. Journal of clinical oncology: official journal of the American Society of Clinical Oncology 2006, 24(7):1037-1044.

16. Hennessy BT, Hortobagyi GN, Rouzier R, et al. Outcome after pathologic complete eradication of cytologically proven breast cancer axillary node metastases following primary chemotherapy. Journal of clinical oncology: official journal of the American Society of Clinical Oncology 2005, 23(36):9304-9311.

17. Gianni L, Eiermann W, Semiglazov V, et al. Neoadjuvant and adjuvant trastuzumab in patients with HER2-positive locally advanced breast cancer (NOAH): follow-up of a randomised controlled superiority trial with a parallel HER2-negative cohort. The Lancet Oncology 2014, 15(6):640-647.

18. Bozovic-Spasojevic I, Azim HA Jr, Paesmans M, et al. Neoadjuvant anthracycline and trastuzumab for breast cancer: is concurrent treatment safe? Lancet Oncol 2011, 12(3):209-211.

19. Moher D, Liberati A, Tetzlaff J, et al. Preferred reporting items for systematic reviews and meta-analyses: the PRISMA statement. Annals of internal medicine 2009, 151(4):264-269, w264

20. Booth A, Clarke M, Dooley G, et al. The nuts and bolts of PROSPERO: an international prospective register of systematic reviews. Systematic reviews 2012, 1:2.

21. Petrelli F, Borgonovo K, Cabiddu M, et al. Neoadjuvant chemotherapy and concomitant trastuzumab in breast cancer. Anti-Cancer Drugs 2011, 22(2):128-135.

22. Valachis A, Mauri D, Polyzos NP, et al. Trastuzumab combined to neoadjuvant chemotherapy in patients with HER2-positive breast cancer: a systematic review and meta-analysis. Breast 2011, 20(6):485-490.

23. Pizzuti L, Barba M, Giannarelli D, et al. Neoadjuvant Sequential Docetaxel Followed by High-Dose Epirubicin in Combination With Cyclophosphamide Administered Concurrently With Trastuzumab. The DECT Trial. J Cell Physiol 2016, 231(11):2541-2547.

24. Tuxen MK, Cold S, Tange UB, et al. Phase II study of neoadjuvant pegylated liposomal doxorubicin and cyclophosphamide $+/$ - trastuzumab followed by docetaxel in locally advanced breast cancer. Acta Oncol 2014, 53(10):1440-1445.

25. Untch M, Loibl S, Bischoff J, et al. Lapatinib versus trastuzumab in combination with neoadjuvant anthracycline-taxane-based chemotherapy 
(GeparQuinto, GBG 44): a randomised phase 3 trial. The Lancet Oncology 2012, 13(2):135-144.

26. Untch M, Rezai M, Loibl S, et al. Neoadjuvant treatment with trastuzumab in HER2-positive breast cancer: results from the GeparQuattro study. J Clin Oncol 2010, 28(12):2024-2031.

27. Wenzel C, Hussian D, Bartsch R, et al. Preoperative therapy with epidoxorubicin and docetaxel plus trastuzumab in patients with primary breast cancer: a pilot study. J Cancer Res Clin Oncol 2004, 130(7):400-404.

28. Cortazar P, Zhang L, Untch M, et al. Pathological complete response and long-term clinical benefit in breast cancer: the CTNeoBC pooled analysis. The Lancet 2014, 384(9938):164-172.

29. Untch M, Fasching PA, Konecny GE, et al. Pathologic complete response after neoadjuvant chemotherapy plus trastuzumab predicts favorable survival in human epidermal growth factor receptor 2-overexpressing breast cancer: results from the TECHNO trial of the AGO and GBG study groups. Journal of clinical oncology: official journal of the American Society of Clinical Oncology 2011, 29(25):3351-3357.

30. Yoshioka T, Hosoda M, Yamamoto M, et al. Prognostic significance of pathologic complete response and Ki67 expression after neoadjuvant chemotherapy in breast cancer. Breast cancer (Tokyo, Japan) 2015, 22(2):185-191.

31. Wang-Lopez Q, Chalabi N, Abrial C, et al. Can pathologic complete response $(\mathrm{pCR})$ be used as a surrogate marker of survival after neoadjuvant therapy for breast cancer? Critical reviews in oncology/hematology 2015, 95(1):88-104.

32. Bayraktar S, Gonzalez-Angulo AM, Lei X, et al. Efficacy of neoadjuvant therapy with trastuzumab concurrent with anthracycline- and nonanthracycline-based regimens for HER2-positive breast cancer. Cancer 2012, 118(9):2385-2393.

33. Dawood S, Gonzalez-Angulo AM, Peintinger F, et al. Efficacy and safety of neoadjuvant trastuzumab combined with paclitaxel and epirubicin: A retrospective review of the M. D. Anderson experience. Cancer 2007, 110(6):1195-1200.

34. Gavila J, Guerrero A, Climent MA, et al. Efficacy and safety of neoadjuvant chemotherapy with concurrent liposomal-encapsulated doxorubicin, paclitaxel and trastuzumab for human epidermal growth factor receptor 2-positive breast cancer in clinical practice. Int J Clin Oncol 2015, 20(3):480-489.

35. Minotti G, Menna P, Salvatorelli E, et al. Anthracyclines: molecular advances and pharmacologic developments in antitumor activity and cardiotoxicity. Pharmacol Rev 2004, 56(2):185-229.

36. de Azambuja E, Procter MJ, van Veldhuisen DJ, et al. Trastuzumab-associated cardiac events at 8 years of median follow-up in the Herceptin Adjuvant trial (BIG 1-01). Journal of clinical oncology: official journal of the American Society of Clinical Oncology 2014, 32(20):2159-2165. 